\title{
Board of Management Level of Commitment to Implementation of Strategic Planning in Primary Schools in Eldoret East Sub-County, Uasin Gishu County, Kenya
}

\author{
Ben Kipngetich Chelulei Dr. Lydia Kipkoech Dr. Joshua Keter \\ Department of Education management and policy studies, \\ University of Eldoret
}

\begin{abstract}
The uses of Strategic plans in modern institutions have developed indicators of successes in both public and private schools. It enabled stakeholders to define priorities, nature innovation and develop creativity. The study sought to determine the board of management level of commitment to implementation of strategic planning in primary schools in Eldoret East Sub-County. The study employed descriptive research design where the researcher used a $10 \%$ of total target population of 3066 to select 310 BOM members from 62 Primary Schools. The study used $30 \%$ of the total 14 BOM in each school. The study purposively sampled 2 Sub-County Directors of Education and random sampled 15 head teachers from primary schools. Data was collected using questionnaire and interview schedules.Quantitative data collected were analyzed using descriptive statistics such as percentages, frequencies, statistical measures of central tendency and standard deviation. Qualitative data was analyzed by building themes from the data collected based on the objectives. The study established that BOM were committed to ensuring that there were enough classrooms for children in schools. They were also commited to improve literacy on finance in schools. The BOM commits to providing resources for pupils to participate in co-curriculum activities geared towards improved social behavior. The study concluded that BOM members were committed in ensuring that the schools had play field for physical activities. The study recommended that the BOM should consider committing their resources to facilitated modern sanitation facilities for both boys and girls together with adequate offices for teachers and staffroom facilities.
\end{abstract}

Keywords: Board of Management, Strategic Planning, Level of Commitment, Kenya

DOI: $10.7176 / \mathrm{JEP} / 12-3-13$

Publication date: January $31^{\text {st }} 2021$

\subsection{Introduction}

Strategic planning has been adapted and used as a management technique in public and private institutions in Kenya. Mintzberg (2015), explain strategic planning to mean a process through which external and internal factors of an organization are examined leading to plans and programmes for implementation and strategies to achieve them. In addition, Ogunmokun (2011) mentioned strategic planning to mean a set of processes undertaken with an aim of developing organizational indicators that will contribute towards achieving organizational goals and objectives. Since independence; Kenya education system has undergone tremendous education reforms; Ominde report of 1964 on Africanization and National goals of education, Bessey report of 1972 on preservation indigenous language, Gachathi report of 1976 on national objectives of education and policies in Kenya; Mackey report of 1981 on the establishment the Second University, Kamunge report of 1988 on working party on education and training for the next decade and beyond, and Koech report of 1999 on Totally Integrated Quality Education and Training. The Ministry of Education science and Technology strategic plan 2006-2011 was then developed with an aim to offer a framework for addressing the challenges facing the sector now that include relevance of education and educated unemployment.

In Uasin Gishu County, strategic plan 2008-2012 was initiated in the Education Office and developed to implement the KESSP investment programmes under Ministry of Education Science and Technology strategic plan (2006-2011). Moreover, recent studies by Kitonga (2012) in Uasin Gishu County schools indicated that 41\% do not have, $13 \%$ are unaware, $15 \%$ are planning to have and $30 \%$ have functional strategic plans. Odebero (2006) further noted that majority of primary schools in the Uasin Gishu County were organized and operate with no strategic plans despite the requirement of MOEST. Furthermore, BOM in Eldoret East sub-county were faced with problems related to commitment and subsequent implementation strategic plan items. The study by Total Quality Management (TQM) and Quality Assurance Organization (QASO) showed that Eldoret East Sub-County has low performance indicators compared to Eldoret South and Eldoret West Sub-Counties. From QASO (2016) report; lack of appropriate strategic plans has led to massive misappropriation of physical resources, low motivation on pupils and teachers to excel in extra co-curricular activities. Lack of prober strategies in awarding of school tenders by Board of Management (Kitonga, 2012) has led to temporary closure of five schools by parents as results of corruption allegations. Kitonga further noted that Board of Management has not been committed enough to contribute positively towards school development leading to low performance in National Examination. Primary 
to Secondary school transition rates for girls are relatively low compared with boys in $2016-2017$ Form one selection, (QASO, 2016). The current study therefore sought to determine the board of management level of commitment to implementation of strategic planning in primary schools in Eldoret East Sub-County.

\subsection{Level of commitment by BOM to implement strategic plan}

Despite the MOE requirement that all institutions must develop strategic plans, their implementation remains a challenge. As observed by Mutuku and Mutuku (2009) many schools still have low commitment to implementation of strategy. In addition to Wilson, (2007) believes that $66 \%$ of strategies formulated in organizations are not executed at all. This study was determined to investigate challenges facing BOM commitment in implementation of strategic plan in primary schools together with considered possible reasons as to why Strategic Planning are not executed despite being formulated to help in supervision of curriculum.

Kitonga, (2012) observe that after the strategic planning process; many of the plans are left on the shelves to gather dust never to be opened again. In addition, Mutuku, (2009) articulates that strategic plans are never implemented from the scratch thus a lot of time was spent reviewing strategies that have never been implemented. It was important to identify reasons as to way strategic plan are left in the shelves never to be opened again and time scheduled by BOM committed on revenue collection and expenditure in schools.

The budgetary allocation was important with (Clarke, 2008), who notes that the implementation of strategy was not just about devising a management framework but involves the allocation of resources amongst the strategic organization units to facilitate achievement of goals. This study therefore implies how BOM determines the units of budged to facilitated adequate resources allocation to teachers and pupils needed in realized in co-curriculum activities.

McShane (2010) have also observed that plans cannot work unless they are tied to budgets and this budget must strictly be adhered to. However, lack of budgeting and limited budgetary allocations to strategic units can hinder the successful implementation of strategies, (Bitange et al, 2010). The study focuses on assessing commitment level of BOM mobilizing adequate resources in the budgets. The study further determines the commitment level of BOM to strictly commit budgetary allocation for successful strategy implementation.

The school system calls for the skills, staff training, and development that are in line with (Mwachia, 2006) who pointed that leadership skills are required of strategic leaders. The study commits to determine the entry level of BOM that include a combination of formal education to a certain level, age, and gender. The study also considers Personnel skills that include commitment level of BOM in the implementation of strategies.

Mutuku (2009) in his study implies therefore that however much financial and physical resources institutions may have, it all depends on how the school BOM marshals them towards achievement of strategic objectives. The study further analyzes whether BOM possess the relevant skills that include commitment towards successful strategy implementation.

Dawson, (2008) considers that organization culture impacts on most facets of the organization's life and it is the context within which strategic plan implementation happen. Thus Wilson (2007), articulate that the culture should be consistence with the strategy being implemented. It implies in this study therefore that strategic BOM must be keen when deriving strategies and strategic objectives of the organization, which should be in tandem with the school culture. In addition, the study examined schools' culture that is an essential part of strategic planning process and that any change proposed must be in line with the culture of the school or else it is bound to fail.

Ngware (2006) for instance observes that culture provides members in the organization identity that generates in them commitment to beliefs and values of the organization, more so the strategic objectives. The study therefore was in agreements with McShane (2010) who articulates that culture facilitates collective commitment in BOM that see strategic plans succeed. These findings are also in tandem with Nickols (2012) who points out that quality and committed staff in an institution leads to successful execution of strategy implementation on school curriculum. The study considers belief and values enshrine in institutional Motto, objectives, and goals in realizing its strategic goals and objectives.

\subsection{Materials \& Methods}

The study employed descriptive research design. The target population was 3066 public primary schools BOM and two Sub-County Executive Officers of Moiben and Ainabkoi. The sample size was 310 BOM who represents $5 \mathrm{BOM}$ from each of the selected 62 primary schools. Simple random sampling was used to arrive at potential schools for study while purposively sampling was used to select 2 County Education Officer from Moiben and Ainabkoi Sub-county. The study purposely used 15 head teachers as key informants from the 62 primary schools. Semi-structured questionnaires were used to collect the data. The statements used in the closed ended part of the questionnaire adopted a 5-point Likert scale "strongly to strongly non-committal". The interviews were recorded using audio recording machine on scheduled time with Key informants. The researcher organized for face-to-face interviews with head teachers and County Education Officers to develop experience and knowledge about BOM level of commitment to implementation of strategic planning in primary schools in Eldoret East Sub-County. 
Camera was used to take photographers of the study area to certain the nature of the topic on questioned. Secondary sources were utilized in the collection of relevant data on the topic. Content validity was used to assess the degree to which the content of a given test was related to the traits for which it was designed to measure (Kothari, 2004). A pilot test was conducted in four of the schools in Eldoret South Sub-county. The research instruments were administered to four schools with five BOM members to give $(4 \times 5)=20 \mathrm{BOM}$ members. A preliminary data analysis was conducted, and the questionnaire submitted to the supervisor. The test-retest techniques were used to test the reliability of the instruments. The researcher administered the instrument to the total respondents in the piloted schools. Reponses were grouped into two groups of odd and even numbers. The responses made were scored on the basis of assigned set. The results were later correlated using Pearson's product correlation co-efficient in order to obtain the reliability of the entire instruments. A correlation co-efficient of about 0.8 was considered reliable.

Data was analyzed using descriptive statistics that include measures of central tendency and standard deviation. The level of commitment, participation responses, challenges and measures to mitigate challenges under study were categorized and each level of the categorical variable was an expected frequency count of at least five. The result was presented using frequency tables, pie chart, line and bar graphs. Percentages were used to determine and explain proportion. Descriptive statistics, frequencies and percentages were used to analyze data. Statistical Package for Social Sciences (SPSS) version 20.0 and excel aided in the analysis. The results from the interviews were transcribed. They were put in themes before reported thematically with the one with highest rate responses given priority just after presentation of quantitative data. Secondary data from education policies booklets augment information from the questionnaire and interviews.

\subsection{Results \& Discussions}

\section{1: Demographic information}

Out of the 310 questionnaires that were issued to the BOM in primary school in Eldoret East sub-county, 158(51\%) were females while $152(49 \%)$ were males. The mean and standard deviation was at $\mathrm{M}=1.51$ and $\mathrm{SD}=0.502$. It was therefore evident from the results that majority were female respondents. Therefore, most women participated as BOM members in various schools in Eldoret East Sub-County. Majority of them $171(56 \%)$ were over forty years of age, $87(28 \%)$ were of the age bracket $36-40$ years, $43(14 \%)$ were of the age $26-30$ years and $9(3 \%)$ were of age less than 25 years. It was further observed the mean and standard deviation of age was $\mathrm{M}=3.37$ and $\mathrm{SD}=0.816$. The results therefore clearly depict that a higher percentage of the members of $\mathrm{BOM}$ are above 40 years. The findings are presented in Table 1

\section{Table 1: Gender and Age}

\begin{tabular}{lcccc}
\hline Indicators & Frequency & Percentage & Mean & Std. dev. \\
\hline Gender & 152 & & & \\
Male & 158 & $49 \%$ & 1.51 & .502 \\
Female & & $51 \%$ & & \\
Age & 9 & $3 \%$ & & \\
$<25$ Years & 43 & $14 \%$ & & \\
$26-30$ Years & 87 & $28 \%$ & 3.37 & .816 \\
36-40 Years & 171 & $55 \%$ & & \\
Over 40 Years & & & & \\
\hline
\end{tabular}

\section{2: Levels of Education and years of Service}

Among the respondents surveyed there was a mean of 1.81 and a standard deviation of 0.757 . The study established that $124(40 \%)$ had certificate as their highest level of education, $124(40 \%)$ had diploma, while only $62(20 \%)$ had bachelor's degree as depicted in the table below. This shows that majority of the respondents surveyed had either diploma or certificate as their highest level of education. This implies that most of the BOM members were somehow educated. Most of them 111 (36\%) have served as members of BOM for three years, 53(17\%) have served for one/two years while only while $93(30 \%)$ have served for more than three years. It was further observed that the mean and standard deviation were $(\mathrm{M}=2.78$ and $\mathrm{SD}=1.056)$ as shown in Table 2. The Education Act (2013) pointed that BOM should holds office for a maximum of three years. This is line with the findings of the study where the results show that nearly three quarters of BOM are serving within the bracket of three years while only $30 \%$ were serving more three years. The findings are presented in Table 2 . 
Table 2: Levels of Education and Years of Service

\begin{tabular}{lcccc}
\hline Indicators & Frequency & Percentage & Mean & Std. dev. \\
\hline Academic qualifications & & & & \\
Certificate & 124 & $40 \%$ & & \\
Diploma & 124 & $40 \%$ & 1.81 & .757 \\
Bachelors & 62 & $20 \%$ & & \\
Years in BOM & & $17 \%$ & & \\
One year & 53 & $17 \%$ & & \\
Two years & 53 & $36 \%$ & 2.78 & 1.056 \\
Three years & 111 & $30 \%$ & & \\
More than three years & 93 & & & \\
\hline
\end{tabular}

\section{3: Level of Commitment in Implementing Strategic Plan by BOM in Eldoret East Sub-County}

The study was then focused on the fulfilment of the first objectives of the study to assess the BOM level of commitment to implementation of strategic planning in primary school in Eldoret East Sub-County. This objective was achieved following the researcher's determination to establish how BOM were committed in ensuring that there was proper and adequate physical facilities, financial management, and curriculum, and instructional roles in Eldoret East Sub-County. The results and discussed are as follows.

\subsection{1: Proper and Adequate Physical Facilities}

Table 3: Proper and Adequate Physical Facilities

\begin{tabular}{|c|c|c|c|c|c|c|c|}
\hline & SC & C & SHC & $\mathbf{U C}$ & SUC & Mean & Std. dev. \\
\hline Factors & Freq\% & Freq\% & Freq\% & Freq\% & Freq\% & & \\
\hline $\begin{array}{l}\text { Classrooms } \\
\text { children }\end{array}$ & $13343 \%$ & $10935 \%$ & $5317 \%$ & $62 \%$ & $93 \%$ & 4.14 & 0.946 \\
\hline $\begin{array}{l}\text { Field of play for } \\
\text { physical }\end{array}$ & $11236 \%$ & $10534 \%$ & $6220 \%$ & $227 \%$ & $93 \%$ & 3.92 & 1.067 \\
\hline $\begin{array}{l}\text { Teachers offices and } \\
\text { staffroom Facilities }\end{array}$ & $10534 \%$ & $11537 \%$ & $5317 \%$ & $289 \%$ & $93 \%$ & 3.92 & 1.043 \\
\hline $\begin{array}{l}\text { Waste disposal } \\
\text { sanitation Facilities }\end{array}$ & $9932 \%$ & $12440 \%$ & $5618 \%$ & $65 \%$ & $65 \%$ & 3.89 & 1.076 \\
\hline $\begin{array}{l}\text { Safe water for drinking } \\
\text { in school }\end{array}$ & $12139 \%$ & $9932 \%$ & $45 \quad 14 \%$ & $124 \%$ & 34 11\% & 3.85 & 1.279 \\
\hline
\end{tabular}

Key: SC-Strongly Committed, C-Committed, SHC-Somehow Committed, UC-Uncommitted, SUC-Strongly

Uncommitted

\subsubsection{1: Classrooms for Children}

Respondents were asked to give their opinions on the level of commitment to implement proper and adequate physical facilities. Based on the results in Table 3 above, most of the respondents were committed to ensuring that there are enough classrooms for children. The study established that most BOM were highly rated as committed in ensuring that there are enough classrooms for children as indicated by both $\mathrm{M}=4.14$ and $\mathrm{SD}=0.946$. In support of this statement, majority of the respondents $133(43 \%)$ were strongly committed in facilitating enough classrooms for children, $109(35 \%)$ were committed, 53(17\%) were somehow committed while only $6(2 \%)$ and $9(3 \%)$ were uncommitted and strongly uncommitted respectively. Clarke, (2008), noted that the implementation of strategy involves commitment of allocating resources to achieve the set goals. This implies that in most schools, BOM are committed in ensuring that children have enough classrooms as indicated in the figure 1.

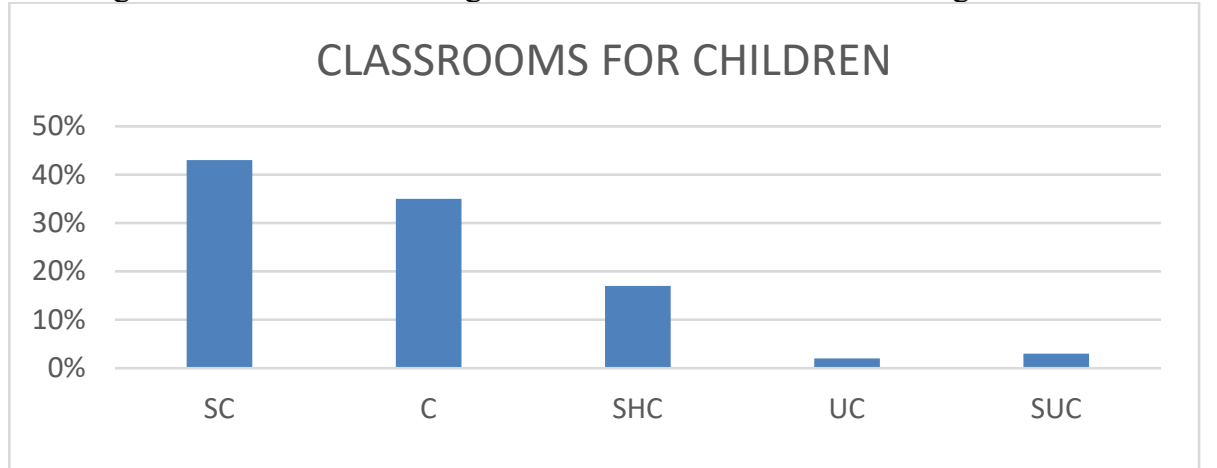

Figure 1: Commitment level on children Classrooms

Key: SC-Strongly Committed, C-Committed, SHC-Somehow Committed, UC-Uncommitted, SUC-Strongly Uncommitted 
It was clear from the findings above than more than three quarters of BOM showed their commitment in strategic planning implementation on classroom for children. Therefore, commitment level of BOM influence positively on provision physical facilities like classrooms in schools. This was in line with the findings by Dawson (2008) which shows that BOM were 70\% very committed in ensuring that there was provision of classroom for children and material facilities by availing funds for physical structures like classroom for children in Kajiado County. This was further supported by the results from interviews where the head teacher in Sosiot primary school affirmed that as a result of BOM commitment, there have been establishments of more classrooms in order to accommodate the current population of 350 pupils. This was further supported by CEO of Moiben who mentioned that children ought to be located in places where school have access to adequate classroom facilities so as to results in higher quality education.

However, commitment by BOM in Usalama and Kimumul primary school was low compared with school classroom facilities and increase enrolment. Head teacher Usalama primary school maintained that the school has not received enough attention from BOM to expand more classrooms for increasing number of children leading to poor quality education. Kimani (2010) as well agreed with the finding by asserting that high enrolment of pupils in schools put pressure on a few facilities within the schools thus pupils were affected by inadequate facilities. In some schools like Mosop and Usalama; the head teachers mention that due to overcrowding of pupils in classrooms, the teachers were forced to conduct lessons outside classrooms. Similarly, Ndegwah (2014) agreed with the finding by reporting that inadequate physical facilities and material resources was the cause of low students' performance in the national examinations.

\subsubsection{2: Field of play for Physical Activities}

The findings were also clear in indicating that most BOM members were committed in ensuring that the schools had play field for physical activities. In this the study, it was found out that while proper and adequate physical activities was a key concern among these schools, at least $112(36 \%)$ and $105(34 \%)$ of the respondents in the study were committed and strongly committed respectively that they could ensure that most schools have play field for physical activities. On the same aspect $62(20 \%)$ were somehow committed while $22(9 \%)$ and $9(3 \%)$ were uncommitted and strongly uncommitted respectively with the statement as indicated in the figure 3 below. This aspect was however supported by most of the individual depicting a mean of 3.92 and a standard deviation of 1.067.

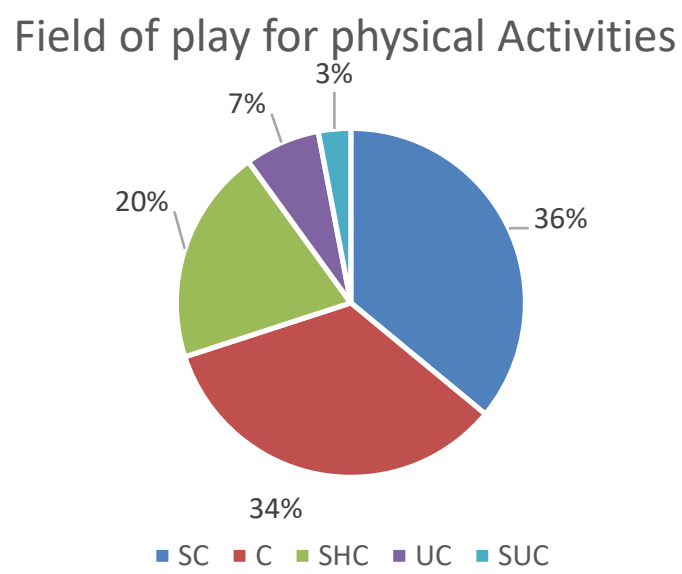

Figure 2: Level of commitment on Field of play for physical Activities

Key: SC-Strongly Committed, C-Committed, SHC-Somehow Committed, UC-Uncommitted, SUC-Strongly Uncommitted

From the findings above, about two thirds of BOM in Eldoret East Sub county primary schools were committed to strategic plan to establishing field of play for physical activities. Therefore, commitment by BOM on strategic plans affects implementation process. For instance, the head teacher for GK Prisons pointed that the school BOM committed adequate finances in facilitating school playground. The head teacher said:- "Children have adequate play ground where both boys and girls actively participating in both games and sports. "In addition, head teacher for Muget primary school pointed that the school has enough playground for children but sharing with existing secondary school. Research findings from Ndegwah (2014) show that physical activities enhance by field of play for physical activities improve academic performance and classroom behaviour.

CEO Moiben argued that the Ministry of Education allocates three PE lessons per week for upper primary level. However, head teacher Kabore primary school reveal that majority of teachers only conducted two lessons in a week due to lack of field of play. This shows that there was a poor commitment of BOM in establishing PE lesson in the school due to inadequate resources. Unfortunately, the head teacher further said that the schools have 
less PE lesson, which implies that the teachers omitted PE programs even though it was scheduled in their timetables. These findings coincide with the findings of Dawson (2008). In her research, Dawson (2008) noted that primary teachers ignore PE lessons in favor of examinable subjects due to lack of resources like field of play. This finding agreed with a study carried out by Mwachia (2009) on school management and students' field of play for physical Activities: How effective are strategies being employed by school managers in schools had revealed that most schools had inadequate physical activities resources and the BOM members were uncommitted on management of school resources.CEO of Ainabkoi Sub County mentions that BOM of any school should commit their roles to create a healthier and happier environment of play for the children diverse needs.

\subsubsection{3: Teacher's Offices and Classroom Facilities}

On the same note in rating BOM as committed in ensuring that there were enough teachers offices and staffroom facilities, the results show range of $(\mathrm{M}=3.92 ; \mathrm{SD}=1.043)$. This was supported by $105(34 \%)$ and $115(37 \%)$ of $\mathrm{BOM}$ who were committed and strongly committed on ensuring there were enough teachers offices and staffroom facilities as illustrated in figure 3 .

\section{Teachers offices and staffroom facilities}

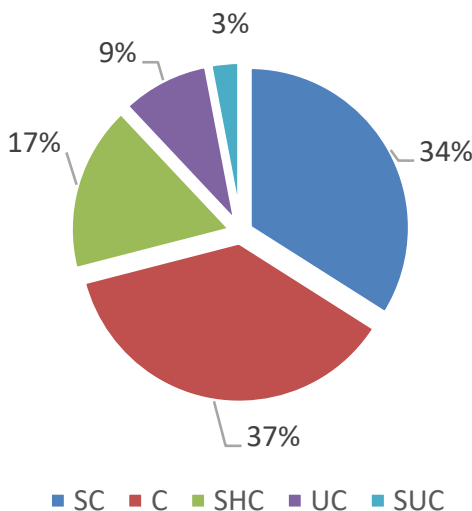

Figure 3: Commitment level on Teacher's offices and staffroom facilities

Key: SC-Strongly Committed, C-Committed, SHC-Somehow Committed, UC-Uncommitted, SUC-Strongly Uncommitted

Considering the commitment level on teacher's offices and classroom facilities more than three quarters of the BOM are committed. Therefore, BOM play important role in ensuring that there was adequate teacher's offices and classroom facilities for teachers. The finding was similar to Kitui West Sub County, (2013) DEO`s Office inspection report who pointed that the Board ensures that there was good or quality education in school by availing necessary resources such as teachers offices and staffroom, teaching and learning materials. Head teacher Marura primary school hails the same by saying that the BOM had committed over ksh200, 000 from FPE for ensuring that teachers get proper table and chairs in their respective staffroom and classrooms. The head teacher Koitorok primary school said that: -

"The BOM so far have committed to providing teachers with chairs, table and cupboards. This has coasted an amount equivalent to Ksh 300,000 to facilitate all classrooms and staffroom with cupboard and chairs."(HT- Koitorok)

However, head teacher Mosop primary school pointed that BOM was not committed enough to facilitate teachers in their respective classrooms and staffroom. In Muget primary school teachers still share desks and tables with children. Classroom facilities that include teachers chairs and table were missing in Kapsoen primary school thus this constantly affected teachers and pupil's performance in national examination. Unfortunately, in some schools in Kenya, Eldoret East Sub County included, staffroom and classroom facilities were missing making teacher uncomfortable when attending to individual child, Mwachia (2009). Ngware (2006) further states that when school equipment and supplies are delayed or missing, teachers cannot be expected to do their work properly. Poor teaching facilities will lead to poor performance by pupils in public exams.

\subsubsection{4: Waste Disposal and Sanitation Facilities}

Furthermore, the rating of BOM as committed in ensuring that there were proper waste disposal and sanitation facilities, the results show range of $(\mathrm{M}=3.89 ; \mathrm{SD}=1.076)$. This was supported by $99(32 \%)$ and $124(40 \%)$ of $\mathrm{BOM}$ who were committed and strongly committed on ensuring there were proper waste disposal and sanitation facilities for children as illustrated in the figure 4 : 


\section{Waste disposal and Sanitation facilities}

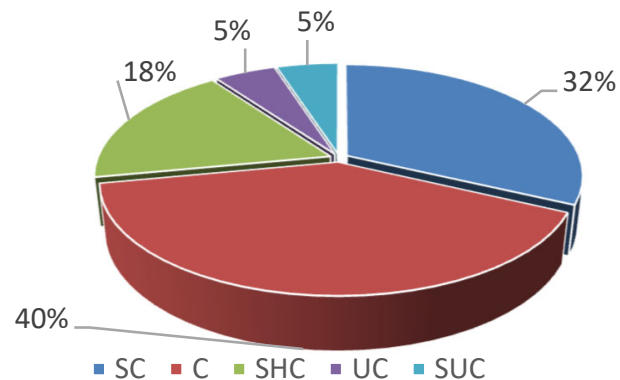

Figure 4: Commitment level on Waste disposal and sanitation facilities

Key: SC-Strongly Committed, C-Committed, SHC-Somehow Committed, UC-Uncommitted, SUC-Strongly Uncommitted

The findings from interviews showed that more than half of BOM in Eldoret East Sub-county are committed to implementation of strategic plan on provision of waste disposal and sanitation facilities. Therefore, the level of commitment has created positive impact on schools. A County Education Officer from Moiben pointed that disposal and sanitation facilities have been a priority for the school. The Head teacher Rotuga primary school said: "So far the school has grown and the BOM has availed sanitation facilities for both boys and girls. The BOM are considering facilitating further modern sanitation facilities and providing girls with adequate sanitary pads for the whole one year". (H/T-Rotuga)

However, lack of budgeting and limited budgetary allocations to strategic units can hinder the successful implementation of strategies (Bitange, Kipchumba, \& Magutu, 2010). CEO of Ainabkoi Sub County claims that lack of commitment by BOM in some schools has led to inadequate access to an improved water supply. Lack of water which was compounded by poor sanitation and hygiene has led to low performance of girls especially those in upper primary who are affected by poor sanitary facilities; "Girls need of privacy during menstrual cycle" explains CEO Ainabkoi. Head teacher Sasitwo primary school argued that BOM hadn't committed adequate resources to improve on sanitation and good hygiene practices in school through construction of gender -sensitive Ventilated Improved Pit (VIP) latrines with separate blocks for boys, teachers and girls, and hand-washing facility. 4.3.1.4: Provision safe drinking water

Even though still above average, safe drinking water in schools was least rated by the respondent with 121(39\%) and $99(32 \%)$ being committed and strongly committed and was further supported with results showing $(\mathrm{M}=3.85$; $\mathrm{SD}=1.279$ ) as illustrated in the summary table 4.3 above and figure 5.

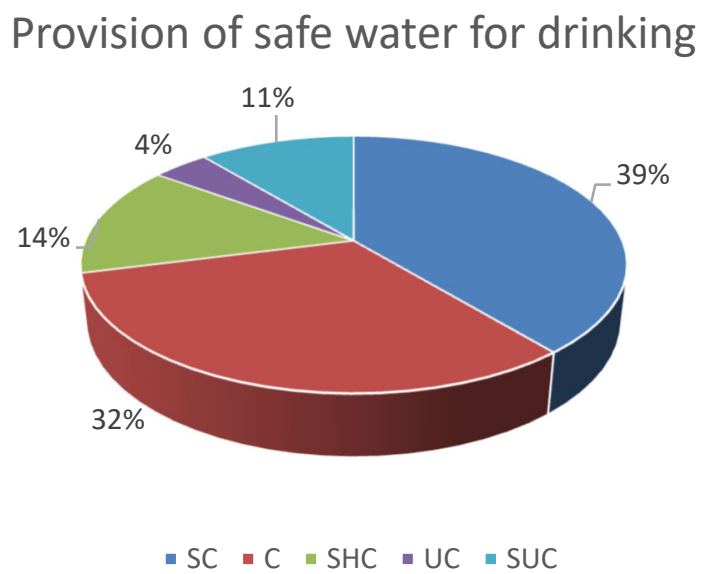

Figure 5: Level of commitment on provision safe drinking water

Key: SC-Strongly Committed, C-Committed, SHC-Somehow Committed, UC-Uncommitted, SUC-Strongly Uncommitted

From the findings, nearly more three quarters of the BOM were committed to strategic plans on provision safe drinking water in primary school. UN-Water, (2006) pointed that strategic plans towards provision of water at schools is one of the highly effective practices in increasing access and learning outcome. In line with Chelagat and other schools in Eldoret Town and environs, BOM are committed to strategies that provide school with safe water for drinking through ELDOWAS Company. The head teacher for Eldoret School said that: 
"The BOM on monthly basis were to pay water bills amounting to over Ksh.10, 000. The ministry of Education had done well enough by bringing to school water treatment plant that is being used at the moment. It provided children safe water for drinking for the whole one week". (H/T-Eldoret)

Peter, (2004) indicated in 2004, 69\% of schools in Kenya had an improved source of drinking water with water available and were therefore classified as providing a basic drinking water service. However, Head teacher Chemalus primary school pointed that the school was in village setup where water comes from either a flowing stream or borehole. Children during dry seasons bring water from their respective homes using 1 to 5 -litters Jericans. Head teacher Muget primary school mentioned that the commitment of BOM in provision of water helped children school to clean their classrooms, watering plants and also for drinking. Furthermore, the Head teacher for Kabore primary school said:

"The school is currently lacking reliable source of safe drinking water. The school depended on borehole, which had already dried up. They used the little water available to clean classes and latrines." (HTKabore)

BOM of Kabore primary school was committed to strategic plan in obtaining treatment plan that uses chemicals that provide safe drinking water for drinking in school. The BOM for Mosop primary school were already frustrated by the process of obtaining license from County Government to develop and setup a school water project. The finding was like Nyongesa (2007) who pointed that the process of executing strategic plans is a complex change. Related to this, there was sufficient empirical evidence which points to the extent that the beneficiaries of strategic plans can be frustrated due to the failure of proper implementation processes followed. The head teacher Mosop said: -

"The project was currently in the last stages but obtaining a three-phase electricity to be used in pumping water from a nearby river, which was $2 \mathrm{~km}$ from the school, is becoming elusive and difficult to secure"(HT-MOSOP)

However, pupils of Kapsoen primary school fetched water from a seasonal stream about 500m away during the wet season, but during the dry spell, they bring water with 5-litre Jericans from their respective homes. The water was not safe for drinking and was used to wet the earthen class floor. In Sosiot primary school pupils carry individual water in small bottles for personal use from their homes. The one permanent and two temporary latrines were inadequate and in poor conditions. There was also no water or soap to wash hands after visiting latrine putting children at risk of contracting germs and diseases (UN-WATER,2006).

\section{4: Financial management}

Following the study findings presented in Table 4, all the statements showing the relationship between financial management and BOM commitment scored high in means with the highest being that; since BOM commitment in strategic planning, there has been improvement on literacy on finance in schools, involvement of parents in budget preparation, preparation of annual reports and on revenue collection and expenditure and Delegation of financial matters at $(\mathrm{M}=3.57 ; \mathrm{SD}=1.149),(\mathrm{M}=3.40 ; \mathrm{SD}=1.288),(\mathrm{M}=3.36 ; \mathrm{SD}=1.285),(\mathrm{M}=3.31 ; \mathrm{SD}=1.157)$ and $(\mathrm{M}=2.96$ $\mathrm{SD}=1.213$ ) respectively.

Table 4: Financial Management

\begin{tabular}{|c|c|c|c|c|c|c|c|}
\hline & SC & C & SHC & $\mathbf{U C}$ & SUC & Mean & Std. dev. \\
\hline Factors & Freq\% & Freq\% & Freq\% & Freq\% & Freq\% & & \\
\hline Literacy level on finance & $5919 \%$ & $13644 \%$ & $6521 \%$ & $227 \%$ & $289 \%$ & 3.57 & 1.149 \\
\hline $\begin{array}{l}\text { Involve parents in budget } \\
\text { preparation }\end{array}$ & $7424 \%$ & $8427 \%$ & $84 \quad 27 \%$ & $31 \quad 10 \%$ & $37 \quad 12 \%$ & 3.40 & 1.288 \\
\hline $\begin{array}{l}\text { Preparation of annual } \\
\text { reports }\end{array}$ & $5919 \%$ & $10534 \%$ & $6220 \%$ & $40 \quad 13 \%$ & $40 \quad 13 \%$ & 3.36 & 1.285 \\
\hline $\begin{array}{l}\text { Revenue collection and } \\
\text { Expenditure }\end{array}$ & $4314 \%$ & $10935 \%$ & $9631 \%$ & $31 \quad 10 \%$ & $31 \quad 10 \%$ & 3.31 & 1.157 \\
\hline $\begin{array}{l}\text { Delagation of financial } \\
\text { matters }\end{array}$ & $227 \%$ & $11236 \%$ & $6220 \%$ & $6521 \%$ & $49 \quad 16 \%$ & 2.96 & 1.213 \\
\hline
\end{tabular}

Key: SC-Strongly Committed, C-Committed, SHC-Somehow Committed, UC-Uncommitted, SUC-Strongly Uncommitted

\subsection{1: Literacy Level on Finance}

The results further shows that majority BOM were commitment in ensuring that there was literacy level on finance with $136(44 \%)$ of them being committed with this statement and 59(19\%) strongly committed on the same. Those who were somehow committed on this aspect accounted for $65(21 \%)$ while $22(7 \%)$ and $28(9 \%)$ uncommitted and strongly uncommitted respectively with the statement as illustrated in figure 6 . 


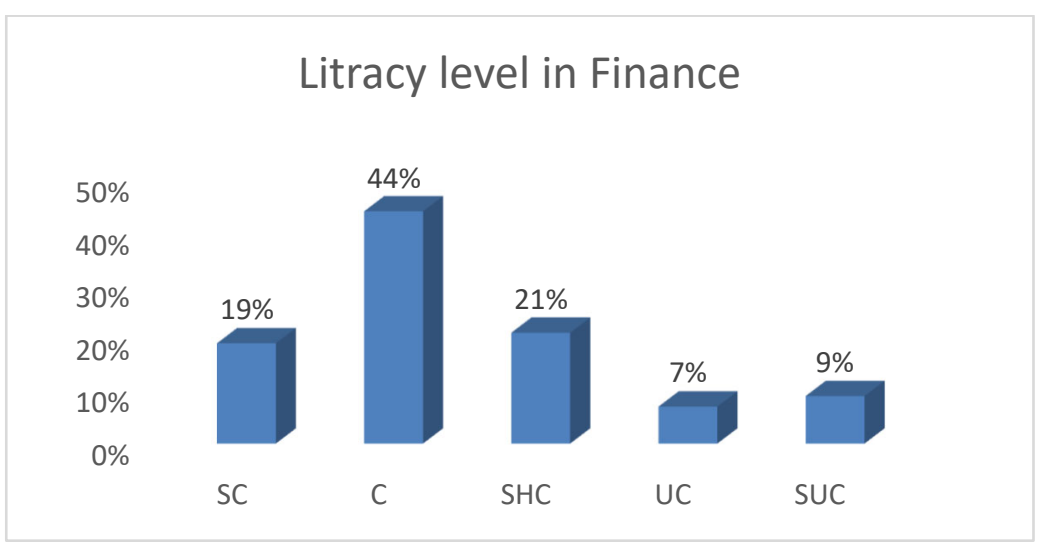

Figure 6: Level of commitment on Literacy level on finance

Key: SC-Strongly Committed, C-Committed, SHC-Somehow Committed, UC-Uncommitted, SUC-Strongly Uncommitted

Finding from interviews indicated that more than two thirds of BOM were committed to strategic plans on literacy level on finances in Eldoret East primary schools. Nyongesa (2007), noted that literacy in financial management will enable the school BOM supervise the preparation of books of accounts, trial balances, and competently deliberate on audited reports. In Eldoret primary school the least academic qualification in the board was degree so the literacy level was high hence they were committed to work while in Chelagat primary, all members of BOM were educated with at least secondary school certificate. They all had knowledge and skills on financial literacy level. According to Mwachia (2009) the skills, staff training, and development were required for strategic leaders and included a combination of formal education to a certain level, appropriate character, relevant experience, and special skills. However in Olare primary school, Head teacher pointed said:

"BOM lacked adequate skills on financial matters since most of them were Form four leavers. They had low literacy level hence affects their commitment level on financial matters. But the county government had held one-day seminar on financial management with them last year 2018." (H/T-Olare).

To enhance commitment and accountability of school finances, County Education Officer of Moiben subcounty highlighted that all finances in the school were managed by BOM and that any financial transactions were subjected to BOM minutes, signed by the chairman and Treasurer. Mobegi, Ondigi and Simatwa (2012), noted that BOM commitment to financial accountability will enable the school management to supervise the preparation of books of accounts, trial balances, and competently deliberate on audited reports.

\subsection{2: Involving Parents on School Budget Preparation}

The results showed majority of BOM who were committed in ensuring that parents were involved in budget preparation were $74(24 \%)$ being strongly committed and $84(27 \%)$ both indicating committed and somehow committed. The uncommitted and strongly uncommitted accounts for $31(10 \%)$ and $37(12 \%)$ respectively as illustrated in the figure 7.

\section{Involving parents in budget preparation}

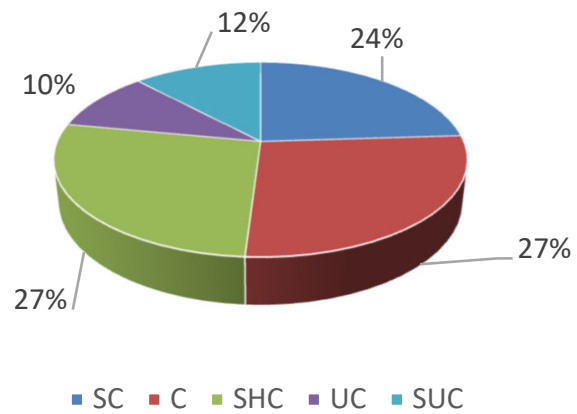

Figure 7: Level of commitment on Involving parents on school budget preparation

Key: SC-Strongly Committed, C-Committed, SHC-Somehow Committed, UC-Uncommitted, SUC-Strongly Uncommitted

From the finding's half of BOM of Eldoret East Sub County was committed in ensuring that parents were involved in budget preparation annually. The results from interviews showed that Eldoret primary school BOM were committed in involving parents on school budget preparation at the end of every year to source for school 
revenue. Chelagat and Sasitwo primary school head teachers reported that out of the 14 BOM, 6 came from parent's representatives. Therefore, they were committed to prepare budget and delivering it to parents in the annual general meeting held at the end or at the start of the year. This was done in accordance to the financial procedures laid down by the government that the standard should then be measured by school self-assessment and by external assessment programme. School head teachers should confirm their schools are compliant, or taking steps to comply with the standard, and sign a declaration at the end of each financial year advising on what arrangement are in place to ensure that their schools meet the standards and to remedy any shortfalls (MOE, 2003). Moreover, Koitorok primary school BOM made a commitment that the school budget be prepared and summit to parents for approval. Any disapproval from parents was considered and the BOM made necessary adjustment. Currently, BOM were on their way to making this year budget as they waited FPE funds declare the head teacher. These findings concurred with Ngware and Kosimbei (2006) who said that that through a strategic plan a school can be effective because it helps to identify and express goals, key improvement strategies, action plans and, finally, monitor and evaluate the school's progress for the purpose of change management.

However Sosiot, Muget and Olare primary school BOM were not committed to involving parents on school budget preparation since they lack strategic plan on involving parents on school budget preparation. The CEO for Moiben pointed that many parents therefore do not know what the money they pay to schools does due lack of strategies on school finances. Mobegi, Ondigi and Simatwa (2012) pointed that this has led to mistrust of the school BOM, loss of goodwill by parents and sponsors and reduced morale among teachers and staff. In the same noted the CEO Ainobkoi said that;

"This has created a situation of total mistrust between the stakeholders, principals being interdicted on allegations of financial misappropriations, students striking or involving themselves in insidious conduct because of the opaque nature of school financial reports or general lack information and cases of poor financial management" (CEO-Ainobkoi).

\subsection{3: Annual Report on Revenue Collection and Expenditure to Parents}

The results further showed that majority of BOM were committed in ensuring that there was preparation of annual reports on school business with $59(19 \%), 105(34 \%), \quad 62(20 \%), \quad 40(13 \%)$ and $40(13 \%)$ being strongly committed, committed, Somehow committed, uncommitted and strongly uncommitted respectively as shown illustrated in figure 8 .

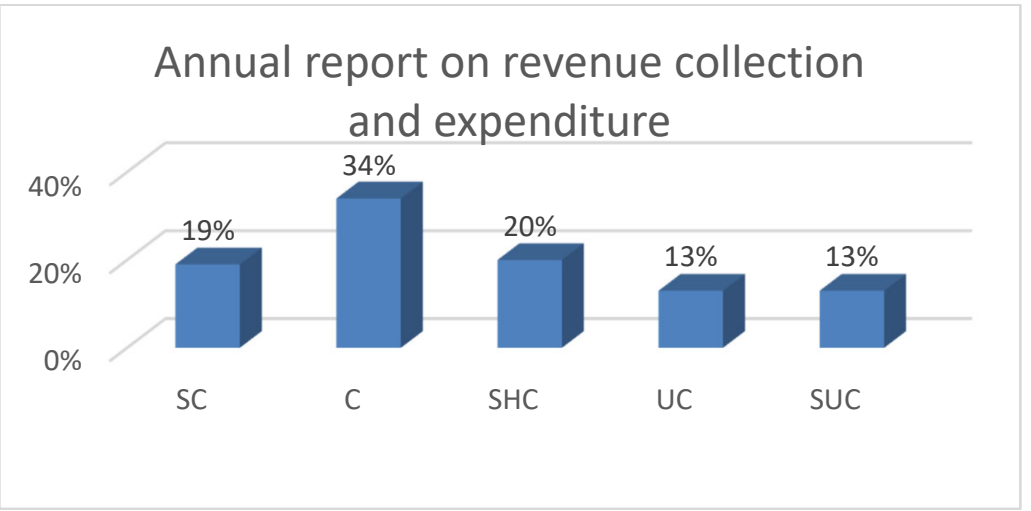

Figure 8: Level of commitment on Annual report on revenue collection and expenditure to parents Key: SC-Strongly Committed, C-Committed, SHC-Somehow Committed, UC-Uncommitted, SUC-Strongly Uncommitted

The results show that more than half of BOM is actively committed to ensuring that preparation of annual report relating to revenue collection and expenditures to parents. Therefore commitment by BOM has a positive impact on annual report on revenue collection and expenditure to parents. The results from interviews showed that in UOE primary school, BOM were committed in preparation of annual report on revenue and expenditure at the end of every year where accounts clerk and BOM guided parents through it. In Chelagat primary school BOM communicate such matters of finance to parents on regular basis and particular at end year basis thus Nickols (2012) increases trust and faithfulness to school BOM to parents. However, in Koitoror Primary School BOM don't consistently review on annual report to parents on collected revenue and expenditure. As a matter fact they were planning to publish last year report on all finances received and spend in the school. In addition, Sosiot primary school didn't report such financials matters to parents in many occasions but as an element of accountability and transparency the school was embarking on reporting financial position to parents by ensuring that every parent gets a copy of balance sheet at the end of every year.

\subsection{4: Collection of Revenue and Expenditure for the School}

It was further found out that BOM were committed in ensuring there was revenue collection and expenditure in school were $43(14 \%), 109(35 \%), 96(31 \%), 31(10 \%)$ and $31(10 \%)$ being strongly committed, committed, 
somehow committed, uncommitted and strongly uncommitted, respectively. This was supported by a mean of 3.31 and standard deviation of 1.157 as illustrated in figure 9 .

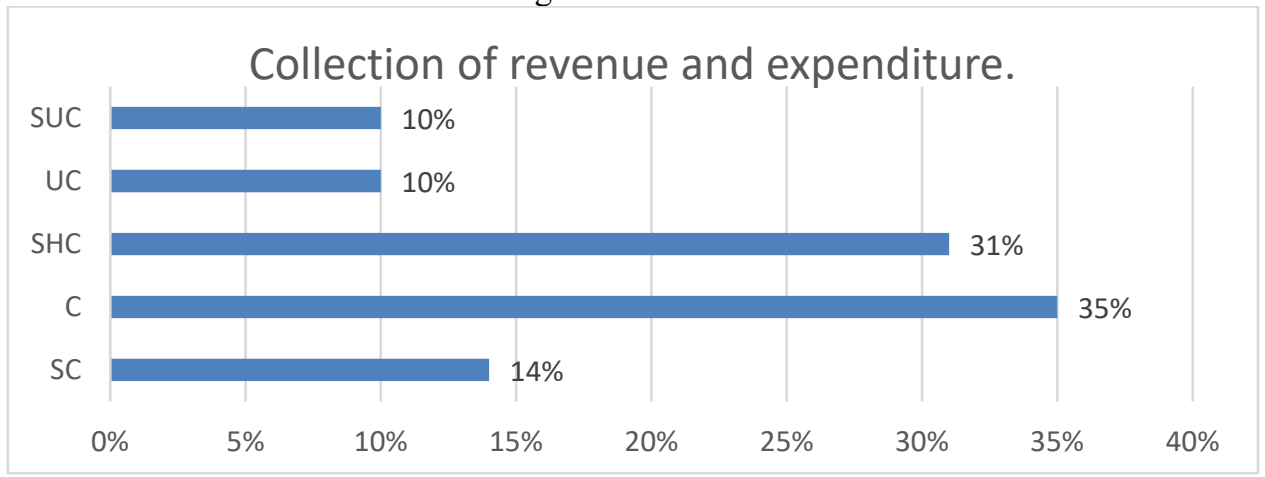

Figure 9: Level of commitment on Collection of Revenue and Expenditure for the School

Key: SC-Strongly Committed, C-Committed, SHC-Somehow Committed, UC-Uncommitted, SUC-Strongly Uncommitted.

From the finding BOM commitment on revenue collection and school expenditure was below average. In Sasitwo primary school commitment of BOM in collection of school finances and expenditure was relatively low. The head teacher of Chemalus primary said: -

"While the head teacher facilitated the disbursements of funds by the government through FPE, $B O M$ do not participate in the collection of revenue as all finances were given and audited by the government." (HT-Chemalus).

County Education Officer of Ainabkoi pointed that the money sent by government through FPE programme has became the only source of finance to various schools. Usalama primary school BOM comprises of committee that are committed to foresee any revenues and expenditures of the school. In Kabore primary school the school had enough Acreage of Land and the BOM were strategizing how to commit more of finances to improve on the school sources of income. However, in Muget primary school the school entirely depended on the government money since they were not allowed to collect revenue from parents. In agreement, Mobegi et al. (2012) pointed that under the free primary school education policy, grants are drawn from tax dollars and then distributed directly to all government primary schools. Every child who attended one of these schools is allocated KES 1420 (about US\$14) a year.

\subsection{5: Delegate Financial Matters to Clerks, Teachers and Treasure}

It was also found out that BOM commitment on delegation of financial matters was the least rated by the respondents with a mean of 2.96 and standard deviation of 1.213 . This was supported by $22(7 \%)$ and $112(36 \%)$ strongly committed and committed respectively while 62(20\%) were somehow committed, 65(21\%) uncommitted and $49(16 \%)$ strongly uncommitted with this statement as illustrated in Figure 10.

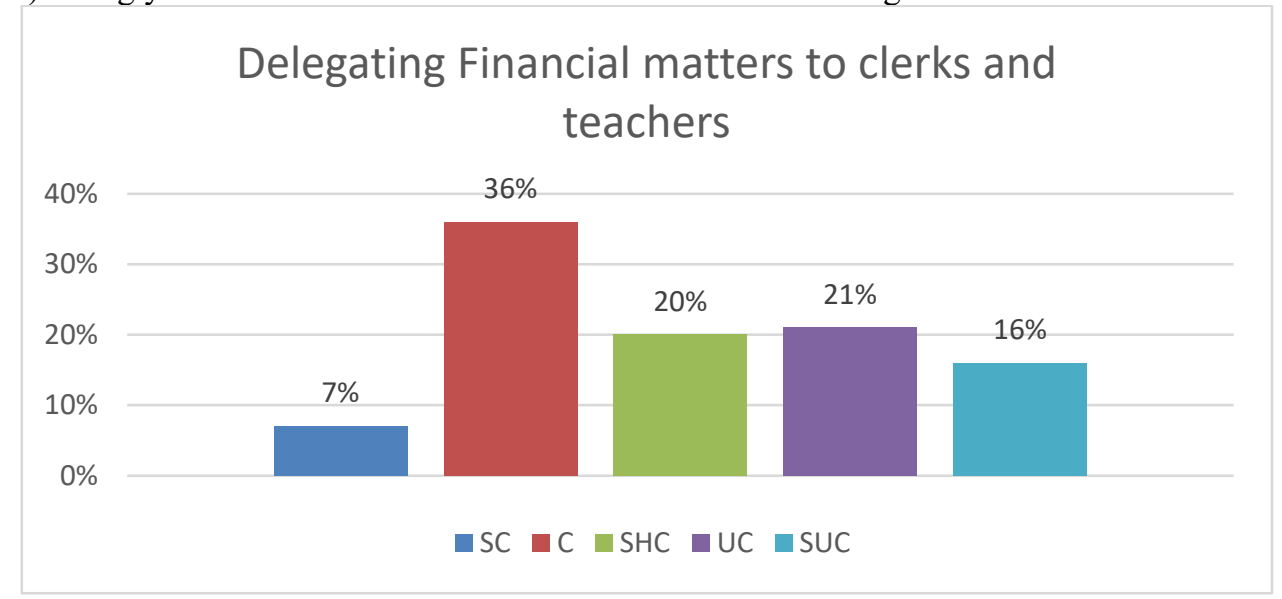

Figure 10: Level of Commitment to Delegate Financial Matters to Clerks and Teachers

Key: SC-strongly committed, C-Committed, UC-Uncommitted, SHC-somehow committed, SUC-strongly uncommitted

From the findings, less than half of BOM are committed in delegation of financial matters to Clerks, teachers, and treasurers. Therefore commitment by BOM on their roles has little impact on delegation of financial matters to clerks, teachers and treasure. In Emsilies primary school, school did not have accounts clerks and therefore 
BOM were committed to ensuring efficient utilization of FPE funds. Also, in Kabore primary school, delegation of finances to office clerk at primary level was not available.CEO for Moiben Sub County pointed that the head teacher and BOM were to run school finances and summit such report to the government on monthly basis and to undertake training on matters concerning school finances. However, while in Eldoret Primary School all matters to do with delegation of finances were handled by school accounts clerk, the Ministry of Education (2013) recognizes head teacher to be school executive officers together with school committee. They were the only persons mandated in public primary school to handle school finances. But it was important that the government saw the need of employing accounts clerk to help head teacher on financial matters as argued by head teacher Kimumul primary school.

\section{5: Curriculum and Instructional materials}

As portrayed by the study findings in Table 5 it was evident that BOM were also committed in providing curriculum and instructional materials. As found out in the study, BOM were committed in providing resources for involving pupils participate in co-curriculum activities, curriculum sustainability, supervising syllabus coverage, monitoring CATs and reporting to parents on academic performance (M=3.78; SD1.207), $(\mathrm{M}=3.57$; $\mathrm{SD}=1.159),(\mathrm{M}=3.56 ; \mathrm{SD}=1.241),(\mathrm{M}=3.50 ; \mathrm{SD}=1.145)$ and $(\mathrm{M}=3.49 ; \mathrm{SD}=1.138)$ respectively.

Table 5: Curriculum and Instructional Materials

\begin{tabular}{|c|c|c|c|c|c|c|c|}
\hline & SC & C & SHC & $\mathbf{U C}$ & SUC & Mean & Std. dev. \\
\hline Factors & Freq\% & Freq\% & Freq\% & Freq\% & Freq $\%$ & & \\
\hline $\begin{array}{l}\text { Involve pupils to } \\
\text { participate in co- } \\
\text { curriculum activities }\end{array}$ & $10935 \%$ & $9029 \%$ & $7025 \%$ & $258 \%$ & $227 \%$ & 3.78 & 1.207 \\
\hline $\begin{array}{l}\text { Resources for curriculum } \\
\text { sustainability }\end{array}$ & $6822 \%$ & $11537 \%$ & $6822 \%$ & $3712 \%$ & $227 \%$ & 3.57 & 1.159 \\
\hline $\begin{array}{l}\text { Supervise } \\
\text { coverage }\end{array}$ & $7123 \%$ & $12741 \%$ & $5016 \%$ & $3110 \%$ & $3110 \%$ & 3.56 & 1.241 \\
\hline Monitoring CATS & $6521 \%$ & $10935 \%$ & $6521 \%$ & $5919 \%$ & $124 \%$ & 3.50 & 1.145 \\
\hline $\begin{array}{l}\text { Report to parents on } \\
\text { academic performance }\end{array}$ & $7424 \%$ & $11838 \%$ & $6521 \%$ & $3712 \%$ & $165 \%$ & 3.49 & 1.138 \\
\hline
\end{tabular}

Key: SC-Strongly Committed, C-Committed, SHC-Somehow Committed, UC-Uncommitted, SUC-Strongly Uncommitted

\subsection{1: Involving pupils participate in co-curriculum activities}

One of the fundamental aspects that stood out on this study was BOM commitment in involving pupils to participate in co-curriculum activities $(\mathrm{M}=3.78 ; \mathrm{SD}=1.207)$. On this aspect most of the BOM showed a strong commitment $109(35 \%)$ with $90(29 \%)$ committed to the statement while only $70(25 \%)$ were somehow committed neither. At least 25(8\%) and 22(7\%) were uncommitted and strongly uncommitted respectively with the statement as illustrated in the figure 11 .

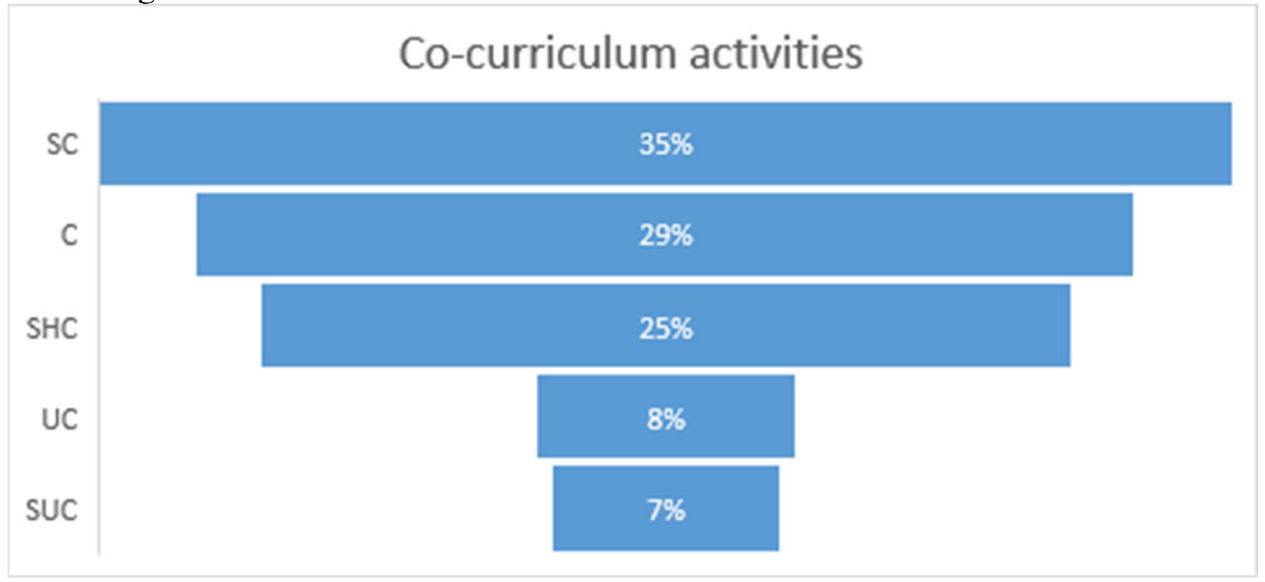

Figure 11: Level of commitment on Involving pupils participate in co-curriculum activities

Key: SC-Strongly Committed, C-Committed, SHC-Somehow Committed, UC-Uncommitted, SUC-Strongly Uncommitted

From the finding more two thirds of BOM in Eldoret East Sub County are committed to involving pupils to participate in co-curriculum activities. Therefore, it was important to note that commitment of BOM in pupil's activities to participate in co-curriculum activities has positive impact. Educationists say co-curricular activities 
play a vital role in helping children develop their personality (Peter, 2004).CEO for Moiben Sub County informs BOM and School heads gives pupils opportunities to fully participate in co-curricular activities. Head teacher Eldoret primary school said that children had untapped and undeveloped potential and the schools commit to providing opportunities for children to realize culture, arts and sporting activities. The head teacher Eldoret said that: -

"The planned curriculum in school will aim at nurturing the potential of every student right away from class one to class eight. The curriculum aims at developing the intellectual, social and emotional growth of the child, hence the importance of the arts, sports and culture." (H/T-Eldoret)

The head teacher Kuinet primary school inform media houses to commit to tapping into the creative abilities and displays of children shown in drama and music festival and air them in their media platforms. The head teacher said that: - "To have the good news of our children appreciated by media audiences of our media houses and in such activities help to instill right values in the learners."

However, COE for Ainabkoi cautioned the head teachers and BOM against hiring strangers to represent their schools thereby denying their learners opportunities to exploit their talents and abilities. Rotuga, Sasitwo and Mosop scooped $3^{\text {rd }} 6^{\text {th }}$ and $7^{\text {th }}$ position respectively in the Play category for primary schools; Eldoret and other urban school monopolized first position in play, narrative solo verse and modern dance categories. Covin, Slevin, and Schulz (2015) in their study found out that students ${ }^{\text {ee }}$ involvement in co-curricular activities enhances their competencies in the four areas tested, namely communication, cognitive, managing self, and academic competency. They argued that significant steps must be taken to ensure that every student participates actively in co-curricular activities, which are headed by teachers who are knowledgeable about that particular activity. Usalama and Soliat Primary School scooped first position in the traditional folk-dance category among primary schools while Emsilies and Kabore scooped first position in the Cultural Dance category in the recent county Music festival held in Central primary school in Eldoret town.

\subsection{2: Resources for Curriculum Sustainability}

Based on these findings, BOM showed approval for their commitment in providing resources for curriculum sustainability with $68(22 \%)$ and $115(37 \%)$ being strongly committed and committed respectively. In support of this statement, there were further $68(22 \%)$ respondent who were somehow committed while only $37(12 \%)$ and $22(7 \%)$ were uncommitted and strongly uncommitted respectively as illustrated in figure 12.

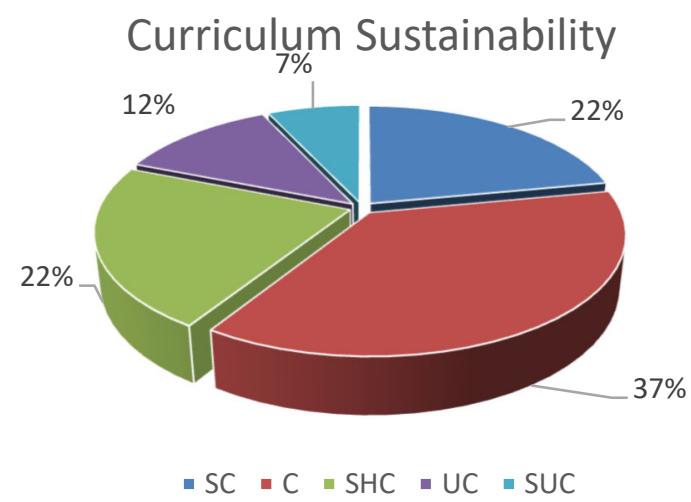

Figure 12: Level of commitment on Resources for Curriculum Sustainability

Key: SC-Strongly Committed, C-Committed, SHC-Somehow Committed, UC-Uncommitted, SUC-Strongly Uncommitted

From the finding two thirds of BOM in Eldoret East were committed to ensuring that there were enough resources for curriculum sustainability. Kimani (2010) did a study on the influence of BOM' commitment in resource management on pupils' performance in Kenya Certificate of Primary Education (KCPE) in public Primary schools in Imenti South District indicated a rise of school mean scores and an increase in pupils enrolment to secondary level for a period of five years successively. Head teacher Kabore primary school pointed that BOM had committed adequate finances towards ensuring adequate supply of text books through FPE programme. The head teacher pointed that: -

"The FPE programme fund that BOM had committed to teachers has help provide teachers with enough stationary like pens, chalks, books and dusters for the whole one year, while all children are provided with exercise books and pens from FPE Funds. " (H/T-Kabore)

Mosop primary school head teacher reported that FPE programme provides books to schools. The head teacher mentioned that: -

"BOM are committed to providing teachers regularly through FPE programme with adequate T/L resources for curriculum sustainability while children are supplied with text and exercise books. Teachers 
and pupil's performances were enhanced since BOM were committed to ensuring that learning process is not interfered with." (H/T-Mosop)

\subsection{3: Supervision of Syllabus Coverage}

Based on these findings $71(23 \%), 127(41 \%)$ and $50(16 \%)$ were strongly committed, committed, and somehow committed respectively on the fact that BOM are committed in supervision of syllabus coverage. In addition, some BOM showed disapproval for their commitment in providing resources for Supervision of syllabus coveragewith $31(10 \%)$ in both being uncommitted and strongly uncommitted as illustrated in the figure 13 below.

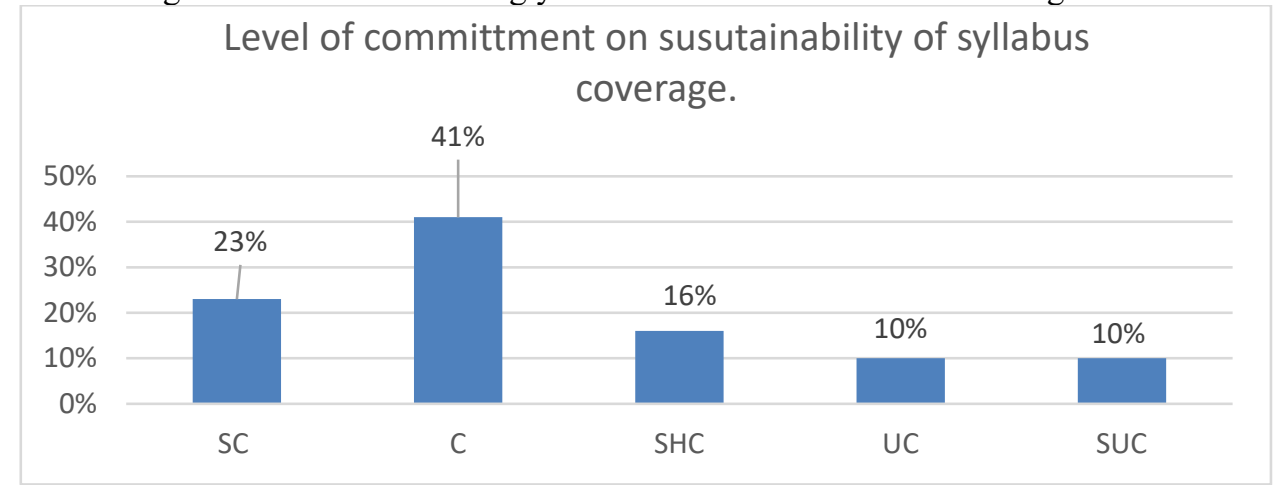

Figure 13: Level of commitment on Supervision of syllabus coverage

Key: SC-Strongly Committed, C-Committed, SHC-Somehow Committed, UC-Uncommitted, SUC-Strongly Uncommitted

The findings from interviews showed that more than three fifth of BOM in Eldoret East sub-county were committed to ensuring that supervision of syllabus coverage was update. Head teacher Kimumul primary confirmed that BOM have committed an average of 2 hours per week for supervision curriculum. In addition, they were committed to ensuring that teachers on normal duty developed cognitive and psychomotor skills in their respective class and also developed current professional documents that included schemes of work, lesson plans and records of work covered. In addition, head teacher for Soliat primary school together with BOM reviewed with teachers' syllabus coverage on monthly basis. The head teacher said:

"In this term BOM have committed at least $30 \%$ of the syllabus to be covered. BOM and teachers are meeting regularly to access the extent of coverage of syllabus. BOM takes part through what teachers are undertaking in their respective classrooms." (H/T-Soliat)

\subsection{4: Monitor Continuous Assessments Test}

From the table above, while 65(21\%), 109(35\%) and $65(21 \%)$ were strongly committed, committed, and somehow committed in the Monitoring CATS. While Fifty-nine (19\%) and 12(4\%) disapproved their level of commitment in ensuring monitoring of Continuous Assessment of Test (CAT) in schools as illustrated figure 14. Nickols (2012) defines monitoring as a process whereby the progress of activities is regularly and continuously observed and analyzed in order to ensure that the expected result is achieved. It is done by regular collection and analysis of information for checking the performance of the programme activities.

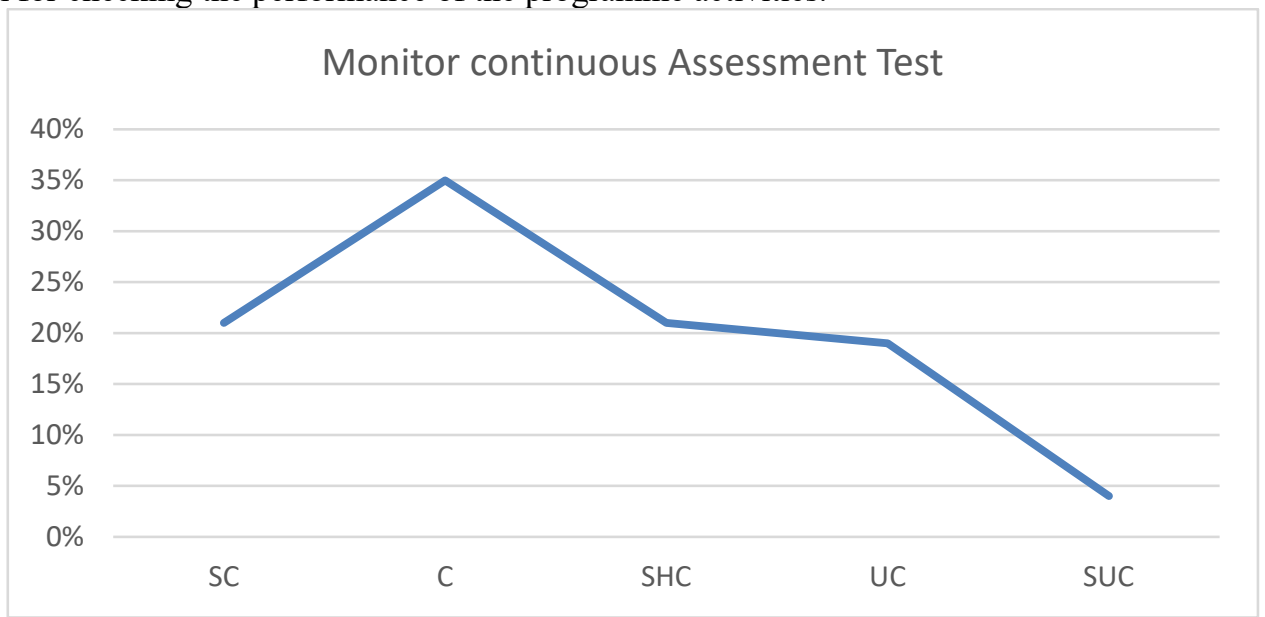

Figure 14: Level of commitment on Monitor Continuous Assessments Test

Key: SC-Strongly Committed, C-Committed, SHC-Somehow Committed, UC-Uncommitted, SUC-Strongly Uncommitted

From the finding more than a half of BOM in Eldoret East Sub County were committed to facilitating the monitoring and evaluation of Continuous Assessments Test (CAT). BOM of Sosiot visits the school on regular 
basis to oversee the school performance. The head teacher pointed that BOM attends to closing ceremony each and every term. BOM are committed to at least two CAT to be administered to pupils in each month to assess the level of knowledge, skill and attitude in pupils. The head teacher for Kimumul primary reported that since there was a ban on commercial exams, teachers set their own and administered to pupils. Head teacher Eldoret on similar occasion mentioned that teachers do midterm evaluation, which it didn't, involved any financial implication on parents. But in Mosop, BOM doesn't inform parents of the importance of examining children. Parents are to pay Ksh.20 per paper to buy standardized paper for children to do. BOM on the same school don't commit to involve parents in awarding children or motivating them through their hard work as indicated by head teacher. In Usalama primary the BOM had committed to timely schedule of CAT, which was to be done three times a term but later withdraw it commitment due to lack good leadership. Parents were not invited to attend awarding ceremony where they were to be made to understand the performance of their children. BOM in Koitorok primary are not committed in ensuring that development of classroom-based evaluation was up to date where marks attained by pupils were to be forwarded for analysis within a week.

\subsection{5: Report to Parents on Academic Performance}

It was also found out that BOM commitment on report to parents on academic performance was the least rated by the respondents with a mean of 3.49and standard deviation of 1.138 . This was supported by $74(24 \%)$ and118 $(38 \%)$ strongly committed and committed respectively while $65(21 \%)$ were somehow committed, $37(12 \%)$ uncommitted and $16(5 \%)$ strongly uncommitted with this statement as illustrated in Figure 15.

\section{Reporting to parents on Academic Performance}

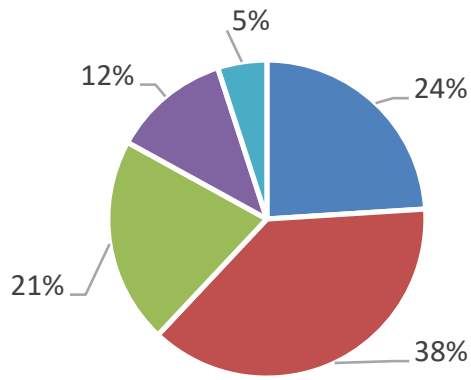

$\because \mathrm{SC}\|\mathrm{C}\| \mathrm{SHC}\|\mathrm{UC}\| \mathrm{SUC}$

Figure 15: Level of commitment on Reporting to Parents on Academic Performance

Key: SC-Strongly Committed, C-Committed, SHC-Somehow Committed, UC-Uncommitted, SUC-Strongly Uncommitted

The results from the interviews show that two thirds of BOM in Eldoret East Sub County are committed in ensuring that they report to parents on academic performance. From the findings Kimumul primary school BOM did commit on reporting to parents on academic performance on term basis. Chemalus Primary School BOM does a report to parents on regular basis. This was done on monthly academic day, teacher to parent to pupil performance monitor, on closing days and at the end of the year. However in Kapsoen and Sosiot primary school; BOM through the head teacher attempt to report to parents the children with poor grade but often receive a lot of resistance from teachers and some parents. Pupil's performance should be done with school head teacher and inquiries from the classroom teacher as indicated by Kitonga (2012). The head teacher Kapsoen lack adequate time to offer counseling and guidance towards assisting children improve on their academic results due to heavy workload in the office. Koitorok and Chelugui primary school head teachers together with BOM had develop class assessment records on availability of textbooks but faced with great loss, theft and poorly maintained textbooks in school.

\section{0:Conclusions \& Recommendations}

The aim of this study was to determine board of management level of commitment to implementation of strategic planning in primary schools in Eldoret East Sub-County. In commitment to Proper and adequate physical facilities, the study concluded that the respondents were committed to ensuring there were adequate classrooms for children. It was also found that BOM members were committed in ensuring that the schools had play field for physical activities. In addition, it was found that BOM were committed in ensuring that there were enough teacher's offices and staffroom facilities and proper waste disposal and sanitation facilities. Even though still above average, respondent rated safe drinking water in schools the least. On financial management BOM was commitment in strategic planning, where there was improvement on literacy on finance in schools, involvement of parents in budget preparation, preparation of annual reports and on revenue collection and expenditure in that order. On 
Curriculum and Instructional materials matters, BOM was committed in involving pupils to participate in cocurriculum activities. It was also found out that BOM were committed in providing resources for curriculum sustainability, supervising syllabus coverage, monitoring CATs and reporting to parents on academic performance, respectively.

Based on the findings of the study, the study recommended that the BOM should consider committing strategic plans in facilitating modern sanitation facilities for both boys and girls accommodate increasing school enrolment. The study further recommends that the BOM commit long term strategies for adequate offices for teachers and staffroom facilities. In addition, BOM should be committed to ensuring constructing more classrooms for children as they increase daily. Furthermore, BOM should ensure committing strategic plans for safe water for drinking for improve hygiene in schools. Where there was improvement on literacy on finance in schools, involvement of parents in budget preparation, preparation of annual reports and on revenue collection and expenditure; BOM should develop attainable strategic plans for sustainability of financial management in schools. On Curriculum and Instructional materials matters, BOM should commit to specific strategic plans that involve pupils to participate in co-curriculum activities for improve physical and mental health. The study recommends that BOM commits in providing resources for curriculum sustainability, supervising syllabus coverage, monitoring CATs and reporting to parents on academic performance for greater transition of both girls and boys to higher education. The study suggests that further research be conducted on BOM to develop measurable strategic plans for provision of safe and clean water for drinking in Moiben Sub-County. It can be replicated in the larger Uasin Gishu County. It is also recommended that further research be conducted on BOM to develop strategic plans for monitoring Continuous Assessment Test in Kenya besides Uasin Gishu County.

\section{References}

1. Bitange, R., Kipchumba, A., \& Magutu, P. (2010). The effectiveness of performance appraisal systems in private universities in Kenya: An assessment of Kabarak University performance. African Journal of Business and Management, 1(1), 123-132.

2. Clarke, P. (2008). Challenging the challenged: Developing an improvement programme for schools facing exceptionally challenging circumstances. School Effectiveness and School Improvement, 17(4), 425-439.

3. Covin, J.G., Slevin, D.P., \& Schulz, R.L. (2015). Implementing strategic mission: effective strategic, structural and tactical choices. Journal of Management Studies, 31(1), 81-88.

4. Dawson, H.O (2008). Involvement of stakeholders in the managerial efficiency of schools. Retrieved from http: www.educational media/foreign press/USA access on 24/10/2010

Kenya; a case study of public universities in Kenya. A conference paper presented at the $1^{\text {st }}$ KIM Conference on management, A journal of KIM school of management ISSN

5. Kimani, N. (2010). The importance of 'outsiders' in small firm strategic planning. Academy of Management Journal, 25(1), 80-93.

6. Kitonga, A. (2012). The fifth Discipline, the art and practice of learning organization. Nairobi: Random House.

7. Kothari, C. R (2004). Research methodology methods and techniques (4th ed.). New Delhi: Willy Eastern Limited.

8. Mcshane, L., \& Glinow, V. (2010). Organization behavior: Emerging knowledge and Practicefor the real world (5th ed.). New York: McGraw- Hill/ Irwin.

9. Mintzberg, H. (2015). The rise and fall of strategic planning. New York, NY: The Free Press.Sciences Association (ABBSA).Cairn Australia.

10. Mobegi, F.O., Ondigi, B.A., \& Simatwa, E.M. (2012). Factors contributing to financial mismanagement and misappropriation in Public Secondary Schools in Gucha District, Kenya. Eregi teachers College Kenya. International Journal of Engineering and Management Research, 2(5), 1-19.

11. Mutuku, S and Mutuku, M (2009), Strategic planning in the Higher Education sector of

12. Mwachia, M. T. (2009). Challenges of implementing Ministry of Education Strategic Plan bygirls secondary schools in Nairobi, Kenya [Unpublished masters' thesis]. University of Nairobi.

13. Ndegwah, D. M. (2014). Factors affecting the implementation of strategic plans in public secondary schools in Nyeri County, Kenya. International Review of Management and Business Research, 3(2), 993.

14. Ngware, M., \& Kosimbei, G. (2006). Financing of primary education in Kenya: Costs and options, Kenya Institute for Public Policy Research and Analysis (KIPPRA) Discussion Paper Number 55 (ISBN 9966949 992 2).

15. Nickols, F. (2012). Strategy is a lot of things. Distance consulting. Lacking a good fit with the political context. Public Productivity and Management Review, 23(3), 297-305.

16. Nyongesa, B. (2007). Educational organization and management, Nairobi: Jomo Kenyatta Foundation.

17. Odebero, S. O. (2006). Total quality management in secondary schools in Kenya: extent of practice. Quality assurance in Education. 
18. Ogunmokun, G., Hopper, T., \& McClymont, H. (2011). Strategy implementation and organizational performance: A study of private hospitals. In Proceedings of the Australasian Business and Behavioural Sciences Association Conference (ABBSA 2005) (pp. 20-28). Australasian Business and Behavioural Sciences Association.

19. Peter, D. (2004). Making fast strategic decisions in high-velocity environment. Academy of Management Journal, 32(1), 543-576.

20. Quality Assurance Organization (QASO) (2016). School performance indicators: Transition to Secondary school 2015-2016.Uasin Gishu County.

21. UN-WATER. (2006). Water in a changing world (Vol. 1). Earthscan.

22. Wilson, B. (2007). Strategic Planning. Long range planning, 27(4), 12-24. 